\title{
ParallelyBuilding the S_T_A_R_S_Testers for Samplings Produce Health Care in Clinics Countries OECD
}

\author{
Antonín Cuc* \\ Cybernetics, OHS expert, Europe \\ *Corresponding author: Antonín Cuc, Cybernetics, OHS expert,International Expert in Health and Safety, Europe
}

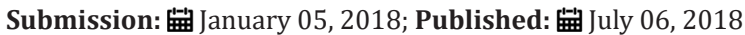

\section{Opinion}

Czech Technical University Prague, Machinary Faculty, Themes: Artificial Intelligence, Decision with risks

The parallely similar structure Mass produce of Health Care for Patients in network Medical Clinics in countries OECD - those are daily Streams of similar Technical and Medical mixed activites in Diagnostics and Treatments of similar structure of diseases of Patients, with similar usage Medical Devices, similar usage prevency of Infects, similar dangerous Medical Processing, similar frequently of usage the same principles of use Medical Radiology, Surgery, Orthopady, Geriatrics, similar prevency of Health risks Patients and similar postoperational Health care.

Unfortunately, the mass-provided Healthcare in OECD's Medical Specialized Clinic Networks clearly brings similarly frequent fatal illegal medical errors, especially in extremely frequent mistakes in the medical use of Medical Devices and in the illegal, frequent commencement of operations of Patients without requiring preoperative sufficient examination of the patient's stabile Health statewithout Checklists the mandatory preparation of the individualized Clinical Plan of the planned next complicated operation.

As a well-educated in Cybernetics and as an State Investigator of fatal work injuries in the illicit use of Medical Devices, I can search detect falsely for fatal medical errors from used Patient Health Records with computer support, and this activity can be easily algorithmized in any similar specialized OECD Clinic, with basic lessons from discontinued medical processes to prevency in future-EX ANTE, especially for the development of usedable deterministic and validated statistical best organisational and medical experiences to share.

I have authored my experiences in Utility Model $21532 \mathrm{CZ}$ of 2010[1] called "The Equipment for Search and Reuse of Sufficient Information for Mass repeated Similar Strategic Decision Making with Risks and Computer support". Because I have become an unnecessary Czech Patient victim of many illegal orthopedic, radiological and forensic medical errors when there were illegal using Orthopedic Implants in Classic Surgeon THA. I want to give you all the basic principles of my Utility Model so that you can start successfully with the parallel building of the probable data models of Health Services yearly production in a likehood OECD clinics. You should arrangedthe Learning Samplings from your yearly produce Health care to run in all participants from TOP Management, Statisticians, Programmers', namely in your specialized progressive Clinic! I wish you World Access!

I have been working on this stochastic model of Production and Support Services called probabilistic, S_T_A_R_S-Testers"because it is a regularly updated random selection from the annual produce of any collaborating Clinic in the OECD network to prevency repeated Medical mistakes. And you can start building on your own interest tomorrow You should be thinking about The Best Practice to manage minimize Patient Risks. With implement continual independent Samplings...I have to die needless earlier with an irreconcilable view of my finished judicial Patient case by the Regional Court Prague No 36 C 181/2009 - this is evidence about wisdom repeating the false arguments of Jusitce CZ, false biomechanical arguments of Medical Court Message CZ[2], false forensic processing in absency of legal independent surveillance of The Criminal Police $\mathrm{CZ}$ and the ignoring my private Civic Human Rights CZ in Justified Court Processing with validated Criminal evidences only - it was refused to correct in next Penalty Court Trials from surveillance to my Constitutional Rights CZ-but with ignoring from net the State Prosecutor's Offices CZ which all categorized my fatal illegal judicial case with illegal accepting biomechanical implanting set THA with fatal illegal Crash in surgeon Hall Dg. Fausse route Stem"into the category of "medical processes for Patient carried with slogan by Legeartis CZ", despite in the Court Medical Message was used them a false stupid medical hypothese to explain surgeon Crash as „The happendpostoperational Patient Fallen", it should be a Model so as my needless inforced Patient Death - it is for Example as a first fundamental world teaching medical and criminal Warning the false interpretation.

The first statistic Unit in the first learning Sample S_T_A_R_S Tester - of Produce Health Care from The Regional Hospital MladáBoleslav CZ since 2007 - contrary correctly logicallybalancing 
and regularly biomechanical testing, controlling the preliminary Health RTG images, etc. There were Criminal Traceing in RTG Patient Health Orthopady Documentation - out of the legality and technical quality of the Laws for Medical implanting Processing stih mandatory individual preliminary Clinic Plan. You should always be guaranted correct legal technical use of Medical devices in everyday medical workflow. This can be seen in a concurrent and independent assessment of updated samples of annual OECD Health Care Networks, such as multi-disciplinary scientific forensic, medical Technical analyzes of archived individual Patient Health Medical Records, rating in my recommending from 3\% proportional collections of all medical yearly Medical Works - such as defined for example in year 2016(Figure 1-3).

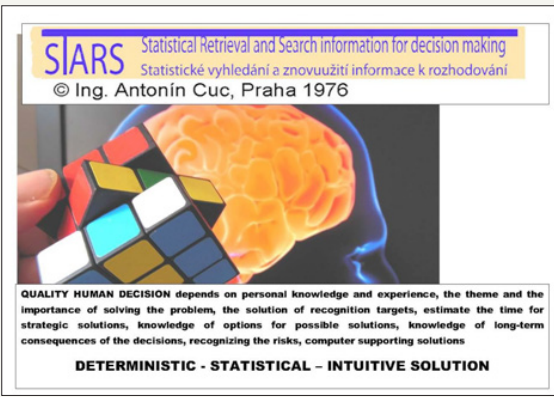

Figure 1.

Figure 2.

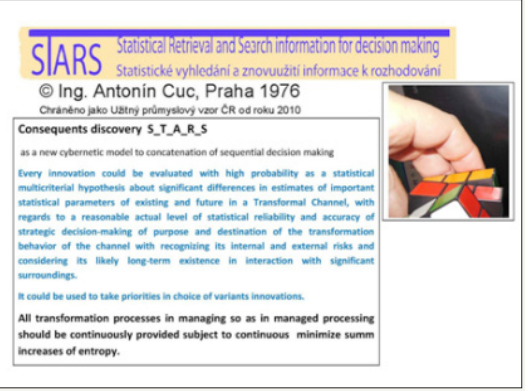

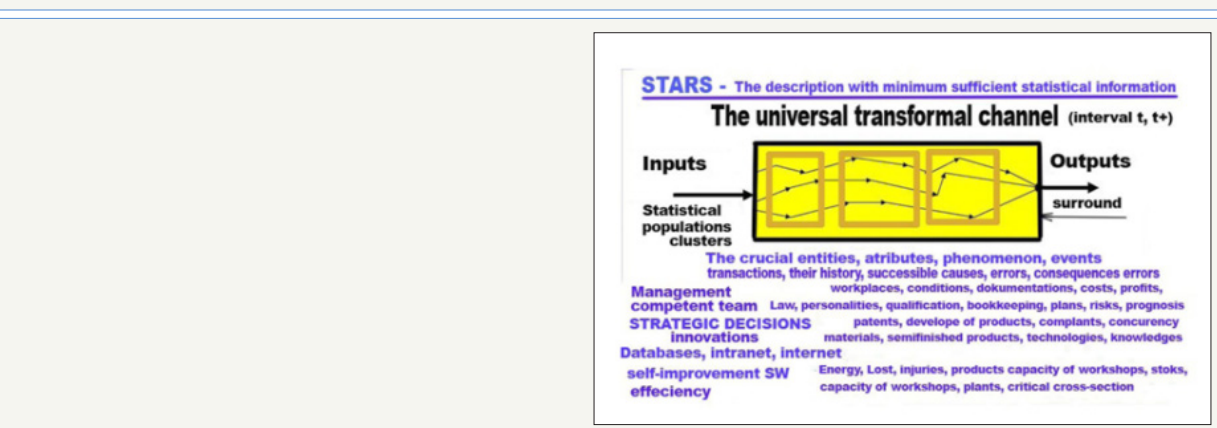

Figure 3.

Your own experience will be undoubtedly fundamentally change speedilythe problem minimizing Patient Risks and interdisciplinary collaboration of various medical expertise in the successful treatment of the individual OECD Patient in similar scientific working Medical Clinics OECD-with sparing the best medical validated experiences only.

\section{References}

1. Antonín Cuc (2010) Utility model 21532 CZ the equipment for search and retrieval sufficient ion formation to mass reuse for similar repeated strategic decision making with risks and computer support.

2. Antonín Cuc (2018) On a criminal trace of crippling and often even lethal false diagnosis: Lege Artis Cz. Orthop and Sport Medicine Op Acc J 1(2): OSMOAJ.MS.ID.000109. 
Creative Commons Attribution 4.0 International License

For possible submissions Click Here

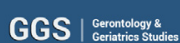

\section{Gerontology \& Geriatrics Studies}

Benefits of Publishing with us

- High-level peer review and editorial services

- Freely accessible online immediately upon publication

- Authors retain the copyright to their work

- Licensing it under a Creative Commons license

- Visibility through different online platforms 